\title{
De jaarrekening van coöperaties
}

Drs. P.J.T.A. van Kleef

\section{Inleiding}

Voor coöperaties gelden de bepalingen ter zake van jaarrekening, jaarverslag en overige gegevens zoals deze zijn opgenomen in BW 2 Titel 9 (artikel 2:360 lid $1 \mathrm{BW}$ ). In een aantal gevallen zijn deze bepalingen echter niet toereikend als gevolg van specifieke aspecten welke voor de coöperaties gelden; dit feit wordt met name veroorzaakt door de bijzondere verhouding tussen de coöperaties en haar leden.

Een coöperatie is een bij notariële akte als coöperatie opgerichte vereniging. De coöperatie moet zich blijkens de statuten ten doel stellen in bepaalde stoffelijke behoeften van haar leden te voorzien krachtens overeenkomsten, anders dan van verzekering, met hen gesloten in het bedrijf dat zij te dien einde ten behoeve van de leden uitoefent of doet uitoefenen (BW2, Titel 3). Het 'voorzien in bepaalde stoffelijke behoeften van de leden' is in hoofdlijnen uitgewerkt in de statuten en veelal nader geregeld in aanvullende overeenkomsten en reglementen. De relatie tussen lid en coöperatie wordt vaak bepaald door het type coöperatie:

- Coöperaties welke de door leden geproduceerde goederen afnemen. De overeenkomsten met het lid kunnen deze verplichten de door haar geproduceerde goederen (melk, land- en tuinbouwproducten, et cetera) aan de coöperatie te leveren, terwijl de coöperatie de plicht heeft deze af te nemen en te (laten) be- of verwerken.

- Coöperaties welke producten en/of diensten aan het lid leveren (inkoopverenigingen, dienstverlening, et cetera). Het lid heeft veelal een grotere keuzevrijheid om de aangeboden goederen of diensten af te nemen.

De werkzaamheden welke coöperaties voor leden verrichten mogen volgens de wet ook voor derden (niet-leden) worden verricht, mits niet in overwegende mate.
Coöperaties worden (in tegenstelling tot vennootschappen) niet opgericht met een minimumkapitaal. De naam van een coöperatie moet het woord 'coöperatief' bevatten; de naam moet aan het einde de letters W.A. (wettelijke aansprakelijkheid), B.A. (beperkte aansprakelijkheid) of U.A. (uitsluiting van aansprakelijkheid) vermelden. Bij W.A. bestaat een volledige aansprakelijkheid (volgens de in de statuten weergegeven verrekenwijze) voor leden en eventueel oud-leden voor een tekort bij ontbinding van de rechtspersoon. Vaak zijn in de statuten ook bepalingen weergegeven voor de verwerking van de jaarlijkse exploitatie en eventuele daaruit voortvloeiende exploitatietekorten.

In dit artikel wordt niet ingegaan op jaarrekeningaspecten van coöperaties welke het bank- of verzekeringswezen uitoefenen omdat hiervoor de voor deze sector geldende specifieke wetten en voorschriften gelden.

\section{Kenmerken van coöperaties}

Onderstaand wordt een aantal kenmerken van coöperaties gegeven welke hun invloed doen gelden op de jaarrekening van coöperaties:

- De betrokkenheid van leden bij het toezicht en de leiding van de coöperatie. Deze betrokkenheid komt tot uitdrukking in de zeggenschapstructuur: ledenraden (vergelijk: algemene vergadering van aandeelhouders), raad van commissarissen (bij de grote coöperaties) en het bestuur dat is ingevuld door leden welke,

Drs. P.J.T.A. van Kleef RA studeerde bedrijfseconomie en accountancy aan de Rijksuniversiteit Groningen en is als partner werkzaam bij Ernst \& Young Accountants en betrokken bij meerdere coöperaties. Hij is met Prof. Drs. A. ten Bos RA auteur van het hoofdstuk Coöperaties in het boek Externe Verslaggeving in theorie en praktijk. 
zeker bij kleinere coöperaties, een belangrijke invloed op de dagelijkse leiding uitoefent.

- Financiering door de leden zowel direct (ledenkapitalen, ledenschulden, et cetera) als indirect via ledenaansprakelijkheid.

- Statutaire en contractuele langlopende overeenkomsten tussen leden en coöperatie.

- De exploitatie is voor rekening en risico van de leden.

Bij grotere coöperaties is de structuur de laatste jaren aangepast waarbij de relatie met de leden in de coöperatie is ondergebracht en de ondernemingsactiviteiten zijn ondergebracht in een vennootschap waarbij de coöperatie vaak enig aandeelhouder is.

\section{De jaarrekening van coöperaties}

Jaarlijks binnen zes maanden na afloop van het boekjaar, behoudens verlenging van deze termijn met ten hoogste vijf maanden door de algemene vergadering op grond van bijzondere omstandigheden, maakt het bestuur een jaarrekening op en legt deze voor de leden ter inzage ten kantore van de coöperatie. Binnen deze termijn legt het bestuur ook het jaarverslag ter inzage, tenzij artikel 403 BW 2 of artikel 396 lid 6 BW2 voor de coöperatie geldt. De jaarrekening wordt, ook indien sprake is van een grote coöperatie (waarvoor het zogenaamde structuurregime geldt, zie artikel 63f BW2, waardoor een raad van commissarissen moet worden benoemd) vastgesteld door de algemene vergadering.

Het Besluit modellen jaarrekening is alleen van toepassing op de naamloze en de besloten vennootschap. Ten behoeve van het te geven inzicht dient het Besluit door coöperaties zoveel mogelijk te worden toegepast.

Met ingang van het boekjaar 2000 is Richtlijn 620 (Richtlijnen voor de Jaarverslaggeving) definitief geworden. Deze richtlijn bevat specifieke eisen voor de jaarverslaggeving van coöperaties. Hierna zal nader worden ingegaan op specifieke zaken betreffende de jaarrekening van coöperaties mede aan de hand van Richtlijn 620.

\subsection{Balans}

Bijzondere aspecten ten aanzien van de balans zijn:

\section{a Eigen vermogen}

Eigen vermogen bij een coöperatie kan belichaamd zijn in op naam staand(e) aandelen, ledenkapitaal, participatiebewijzen, reservebewijzen en dergelijke. Deze vermogenscomponenten kunnen al naar gelang hun aard op naam van leden en/of derden staan. Aan op naam staande vermogenscomponenten kunnen aanspraken op dividend of vermogensgroei gekoppeld zijn.

De niet op naam staande vermogenscomponenten worden vermogen in 'de dode hand' genoemd. Alleen bij liquidatie van de coöperatie kunnen leden rechten doen gelden op dit vermogen in 'de dode hand'. Er bestaat geen aanspraak op deze vermogenscomponenten bij uittreding als lid. Ook kunnen leden in principe geen aanspraken overdragen aan andere (rechts)personen.

De terminologie (ledenkapitaal, participatiebewijzen, reservebewijzen, et cetera) welke wordt gebruikt, is veelal niet eenduidig. In grote lijnen kan een onderscheid worden gemaakt tussen eigen vermogen op naam dat is ontstaan door inhouding van resultaat (reservebewijzen, ledenkapitaal) en eigen vermogen dat door de leden is ingebracht (participatiebewijzen, ledenbewijzen). Een kenmerk van het vermogen op naam is in het algemeen dat bij vertrek van het lid (door bijvoorbeeld bedrijfsbeëindiging) het vermogen moet worden terugbetaald. Het vermogen is tijdelijk in de coöperatie aanwezig. Het risico bestaat dat bij een slechte gang van zaken (in de betreffende coöperatie of in de sector) leden hun bedrijf beëindigen en/of opzeggen en dat daardoor het eigen vermogen 'dubbel' wordt uitgehold: door de slechte gang van zaken geen reserveringen (of zelfs door verliezen een onttrekking aan de reserves) en afname door terugbetaling op naam.

De vermogenscomponenten kunnen als volgt nader worden toegelicht:

- Het eigen vermogen op naam (ledenreserverekening) dat door inhouding resultaat is ontstaan, heeft veelal een tijdelijk (in coöperatieve terminologie: omlopend) karakter. $\mathrm{Na}$ een bepaalde periode (bijvoorbeeld 10 of 15 jaar) vindt uitbetaling plaats van de jaarschijf welke 10 of 15 jaar geleden is gereserveerd; door de aangroei van een schijf inzake het afgesloten boekjaar blijft de reserverekening in principe op peil. Op deze rekeningen wordt veelal geen rendement vergoed.

- Leden- of participatiebewijzen kunnen ontstaan door vrijwillige stortingen of verplichte stortingen door de leden. In het laatste geval is aan het bewijs vaak een leveringsrecht gekoppeld; zonder bewijzen geen leveringsrecht. In bepaalde gevallen kan de waarde van het leden- en participatiebewijs fluctueren met de gang van zaken van de onderneming; de leden delen dan mee in de waardegroei (plus of min) van de coöperatie. 
Indien van vermogenscomponenten niet reeds op voorhand duidelijk is of deze tot het eigen vermogen of tot het vreemd vermogen behoren, dient op basis van Richtlijn 240 (Eigen vermogen), alinea 131 een keuze te worden gemaakt.

Indien het eigen vermogen is samengesteld uit verschillende, veelal statutair bepaalde, categorieën, dient per categorie een mutatieoverzicht te worden gegeven. De op naam van leden en de op naam van derden staande vermogenscomponenten vormen afzonderlijke categorieën, evenals het vermogen in de dode hand. Ofschoon de Richtlijn dit niet vermeldt, verdient het aanbeveling om de betreffende statutaire bepaling samengevat weer te geven teneinde het inzicht in de componenten te geven. Wel geeft de Richtlijn aan dat indien bij het uittreden als lid eigen vermogen moet worden terugbetaald, dit in de toelichting dient te worden vermeld. Zo mogelijk dienen zowel de naar verwachting terug te betalen bedragen als het tijdstip waarop de terugbetaling zal plaatsvinden te worden vermeld. Deze vermelding is nodig om de lezer inzage te geven in aspecten welke de solvabiliteit en liquiditeit kunnen beïnvloeden.

De niet op naam staande vermogenscomponenten worden vermogen in 'de dode hand' genoemd. Leden hebben bij uittreden uit de coöperatie geen aanspraak op dit vermogen. Daarom wordt 'dode hand'-vermogen (en de groei door reservering) vaak kritisch door de leden beoordeeld en dat is een van de redenen dat het laatste decennium vermogensvorming op naam is toegenomen. Anderzijds legt 'dode hand'-vermogen een financiële basis voor de coöperatie, waardoor de ledenaansprakelijkheid kan worden beperkt; bovendien kunnen onvoorziene verliezen (bijvoorbeeld uit fabriekssluitingen of reorganisaties) ten laste van deze reserve worden gebracht waardoor de uitbetaling niet tot een onaanvaardbaar laag niveau daalt (in vergelijking met prijzen welke op de vrije markt of bij concurrerende coöperaties worden uitbetaald). De laatste jaren ontstaat bij coöperaties het gebruik om van nieuwe leden een entreegeld te vragen, vaak als compensatie voor het (indirecte) voordeel dat het nieuwe lid heeft van in het verleden opgebouwde 'dode hand'-vermogen; soms wordt het entreegeld weer bij beëindiging van het lidmaatschap terugbetaald, soms blijft het in bezit van de coöperatie.

Een bijzondere bron voor reservering in het verleden betrof het uittreedgeld; leden die voortijdig (anders dan bijvoorbeeld bij bedrijfsbeëindiging of overlijden) de coöperatie verlieten, dienden uittreedgeld te betalen. Het uittreedgeld diende ter compensatie van capaciteit welke door het vertrek van het lid ongebruikt kwam te staan.
De omvang van het uittreedgeld was vaak gekoppeld aan de waarde van geleverde producten. Door uitspraken van de rechter (tot en met het Europese Hof) zijn deze regelingen veelal beëindigd.

\section{b Ledenaansprakelijkheid}

De vermogensstructuur van een coöperatie kan sterker zijn dan uit de balans blijkt omdat als zekerheid een ledenaansprakelijkheid kan gelden. De ledenaansprakelijkheid dient te blijken uit de toelichting onder 'Overige gegevens'. Een nadere bespreking vindt plaats in hoofdstuk 3.3.

\section{c Vorderingen en schulden}

Het bedrag van de vorderingen op en de schulden aan de leden van de coöperatie dient te worden vermeld in de balans of de toelichting.

Via statutaire regelingen zijn de leden van een coöperatie veelal verplicht om in de financieringsbehoefte op lange(re) termijn te voorzien door rentedragende leningen te verstrekken. Bij de coöperatie worden dergelijke schulden veelal aangeduid als 'ledenschuld'-rekeningen. In sommige gevallen zijn dergelijke schulden achtergesteld. De voorwaarden kunnen van geval tot geval sterk verschillen. Vaak betreffen het ledenschulden met een tijdelijk, omlopend karakter; aangroei vindt plaats door inhouding op de slot- of nabetaling inzake geleverde producten of retributie op afgenomen diensten. Na een bepaalde periode (bijvoorbeeld 10 jaar) vindt uitbetaling plaats van de jaarschijf welke 10 geleden is geleend; door de aangroei van een schijf inzake het afgesloten boekjaar blijft de ledenschuldrekening in principe op peil.

Een belangrijke bron van min of meer permanente korte financiering kan bestaan uit de in de loop van een boekjaar toenemende schuld aan het lid betreffende de slot- of nabetaling of te betalen retributie (een vorm van korting op afgenomen diensten of producten door het lid), welke in de loop van het daaropvolgende jaar wordt uitbetaald.

Bovendien bieden coöperaties hun leden soms de mogelijkheid om gelden niet op te nemen, doch op een ledendepositorekening te plaatsen; het biedt de coöperatie dan een relatief goedkope wijze van kortlopende financiering.

\section{$d$ Voorraden}

Indien onder voorraden goederen uit hoofde van transacties met leden zijn opgenomen, die gewaardeerd zijn op basis van de aan leden (voorlopig) betaalde prijzen (veelal aangeduid als voorschotprijs) of prijzen afgeleid van de opbrengstprijzen en deze prijzen belangrijk afwijken van hetgeen marktconform is, is een nadere toelichting vereist 
ter zake van prijsstelling en waardering.

Opgemerkt zij dat niet in alle gevallen de voorraden welke de coöperatie op haar balans toont ook juridisch haar eigendom zijn. Juristen betogen vaak dat het juridische eigendomsrecht van de van leden 'afgenomen' producten niet overgaat naar de coöperatie, doch rechtstreeks naar de uiteindelijke koper. Strikt juridisch moeten dan in de balans van de coöperatie geen voorraden worden opgenomen, maar een vordering op de leden uit hoofde van betaalde voorschotten.

\subsection{Exploitatierekening}

In artikel 361 lid 2 BW2 is met betrekking tot de winst- en verliesrekening bij coöperaties bepaald dat deze wordt vervangen door een exploitatierekening, indien het in artikel 362 lid 1 BW2 bedoelde inzicht daardoor wordt gediend.

De bepalingen omtrent het vaststellen van winst en verlies zijn zoveel mogelijk van overeenkomstige toepassing op het exploitatiesaldo.

Bijzondere aspecten ten aanzien van de exploitatierekening zijn:

\section{a Indeling van de exploitatierekening}

De indeling van de exploitatierekening volgt vaak in hoofdlijnen de indeling van de winst- en verliesrekening, doch de presentatie van de leveringen door leden kan afwijken. In de praktijk blijkt dat coöperaties op verschillende wijzen de exploitatierekening opstellen, vaak als uitvloeisel van statutaire bepalingen. Het saldo van de exploitatierekening heeft dan ook een specifieke betekenis en moet bij het opstellen worden bezien in relatie tot de gehanteerde uitgangspunten. Het vergelijken van de prestaties van coöperaties is in de praktijk dan ook vaak bijzonder lastig. Onderstaand wordt een voorbeeld gegeven van een exploitatierekening van een coöperatie met ter vergelijking de wijze waarop een vennootschap de cijfers zou hebben gepresenteerd.

De 'kosten' voor de inkoop van grondstoffen van leden worden bij deze coöperatie niet op de betreffende regel verantwoord; wat overblijft na aftrek van kosten en reserveringen wordt als uitkering exploitatiesaldo aan de leden betaald ter vergoeding van de geleverde producten.

Soms toont een exploitatierekening de slot- of nabetaling als saldo; de voor de levering van de producten betaalde voorschotprijzen zijn dan als kosten van grond- en hulpstoffen opgenomen.

Een geconsolideerde exploitatierekening van een coöperatie wordt veelal opgesteld volgens dezelfde rubricering als vennootschappen dat zou-

\section{Coöperatie Vennootschap}

\begin{tabular}{|c|c|c|}
\hline Netto-omzet & 176.147 & 176.147 \\
\hline \multicolumn{3}{|l|}{ Kosten van grond- en } \\
\hline hulpstoffen & - 30.815 & -131.917 \\
\hline Kosten uitbesteed werk & & \\
\hline en andere externe kosten & - 15.347 & -15.347 \\
\hline Personeelskosten & - 13.368 & - 13.368 \\
\hline Afschrijvingen & - $\quad 8.234$ & - 8.234 \\
\hline Bedrijfsresultaat & 108.383 & 7.281 \\
\hline Financiële baten en lasten & $-\quad 1.659$ & 1.659 \\
\hline Saldo / resultaat voor & & \\
\hline belastingen & 106.724 & 5.622 \\
\hline Vennootschapsbelastingen & - $\quad 1.970$ & 1.970 \\
\hline Exploitatiesaldo / & & \\
\hline netto winst & 104.754 & 3.652 \\
\hline Toevoeging aan reserves & $-\quad 3.652$ & $======$ \\
\hline Uitkering aan leden & 101.102 & \\
\hline
\end{tabular}

den doen; in dit voorbeeld wordt de uitkering aan leden dan gerubriceerd op de regel 'kosten van grond- en hulpstoffen'.

\section{b Belastingdruk}

Uit het voorbeeld blijkt dat in de coöperatieve exploitatierekening de relatie belastinglast met saldo voor belastingen ontbreekt. De belastingdruk lijkt bij coöperaties vaak relatief laag, doch dat komt door de wijze van presenteren. Indien de exploitatierekening de slot- of nabetaling als saldo toont, wordt vaak de lage belastingdruk veroorzaakt door het feit dat gebruik wordt gemaakt van de faciliteit van de zogenaamde verlengstukwinst. Deze faciliteit kan worden gerealiseerd, indien binnen gestelde voorwaarden baten uit hoofde van het zakelijk verkeer met de leden van de coöperatie (voor aftrek van vennootschapsbelasting) worden uitgekeerd aan de leden; deze uitkeringen zijn in dit geval belast bij de leden.

\section{c Exploitatierekening}

Indien wordt onderscheiden tussen bijvoorbeeld de exploitatie van de coöperatie zelf (deze bezit dan vaak de vaste activa en heeft het personeel in dienst) en de exploitatierekening waarin de uitkomsten van de voor rekening en risico van de leden gesloten overeenkomsten tot uitdrukking komen, kan het inzicht vereisen dat gesegmenteerde informatie wordt verstrekt. Veel coöperaties nemen dan een tweede exploitatierekening op; deze wordt ook wel als ledenexploitatierekening of dienstverleningsexploitatierekening aangeduid; 
deze exploitatierekening kan als een vorm van poolovereenkomst worden beschouwd. Onderstaand volgt een voorbeeld van een ledenexploitatierekening:

Netto-omzet

176.147

Aan leden in rekening gebrachte

kosten en vergoeding bedrijfsuitoefening

$-75.045$

Exploitatiesaldo

101.102

Uitkering aan leden

\subsection{Toelichting op de jaarrekening}

Zoals uit bovenstaande hoofdstukken blijkt, zal door middel van een toelichting op posten meer inzicht moeten worden gegeven; samengevat betreffen deze:

a Voorraden: indien in de voorraden goederen uit hoofde van transacties met leden zijn opgenomen, die gewaardeerd zijn op basis van de aan leden (voorlopig) betaalde prijzen of prijzen afgeleid van de opbrengstprijzen en deze prijzen belangrijk afwijken van hetgeen marktconform is, is een nadere toelichting vereist ter zake van prijsstelling en waardering.

b Vorderingen en schulden: het bedrag van de vorderingen op en schulden aan leden van de coöperatie dient te worden vermeld in de balans of de toelichting. Indien rond deze vorderingen en schulden bijzondere voorwaarden bestaan, is toelichting wenselijk.

c Indien het eigen vermogen is samengesteld uit verschillende, veelal statutair bepaalde, categorieën, dient per categorie een mutatieoverzicht te worden gegeven. De op naam van leden en de op naam van derden staande vermogenscomponenten vormen afzonderlijke categorieën, evenals het vermogen in de dode hand.

Indien bij het uittreden van een lid eigen vermogen moet worden terugbetaald, dient dit in de toelichting te worden vermeld. Zo mogelijk dienen zowel de naar verwachting terug te betalen bedragen als het tijdstip waarop terugbetaling zal plaatsvinden te worden vermeld.

d Transacties met leden: in de toelichting dient inzicht te worden gegeven in de aard en omvang van de transacties met de leden alsmede, indien dit noodzakelijk is voor het vereiste inzicht, in de relevante aspecten van die transacties. De richtlijn verwijst hierbij naar de

Richtlijn 190, alinea 307, paragraaf 3, inzake verbonden partijen.

Bovenstaande alinea uit de Richtlijn lijkt wat overdreven. De coöperatie heeft juist tot doel om voor rekening en risico van de leden te handelen; anderzijds dient wel duidelijk te blijken welk deel van de inkopen of geleverde producten of diensten uit de ledenrelatie voortkomt. In veel gevallen zal dat rechtstreeks uit de exploitatierekening te lezen zijn (zoals uit de in dit artikel opgenomen voorbeelden blijkt). Het is ook de vraag of een individueel lid als verbonden partij moet worden beschouwd; het lid heeft afzonderlijk geen beslissende zeggenschap.

\subsection{Overige gegevens}

Inzake de bij de jaarrekening en jaarverslag te voegen Overige gegevens is (in BW2, artikel 392, lid 1d) een specifieke bepaling voor coöperaties opgenomen; toegevoegd wordt een weergave van de statutaire regeling omtrent de bijdrage in een tekort van een coöperatie, voorzover deze van de wettelijke bepalingen afwijkt.

In de wet wordt de volledige aansprakelijkheid voor leden voor het tekort van de coöperatie bij ontbinding besproken; deze aansprakelijkheid wordt wettelijke aansprakelijkheid (afgekort W.A.) genoemd. De hoofdregel luidt dat zij die bij de ontbinding leden waren, of minder dan een jaar tevoren hebben opgehouden leden te zijn, tegenover de rechtspersoon naar de in de statuten aangegeven maatstaf voor een tekort aansprakelijk zijn. Bevatten de statuten geen maatstaf voor ieders aansprakelijkheid, dan zijn allen voor gelijke delen aansprakelijk.

Een coöperatie kan in haar statuten iedere verplichting van haar leden of oud-leden om in een tekort bij te dragen, uitsluiten of tot een maximum beperken. In dat geval zijn aan het eind van de naam geplaatst de letters U.A. (uitsluiting van aansprakelijkheid) respectievelijk B.A. (beperkte aansprakelijkheid). Volgens de Richtlijn dient bij de coöperatie met beperkte aansprakelijkheid (B.A.) de omvang van de ledenaansprakelijkheid te worden vermeld.

In de praktijk is de aansprakelijkheid vaak gerelateerd aan door de leden ingebrachte middelen (bijvoorbeeld de storting op ledenbewijzen, omvang van ledenschulden, et cetera) of aan de omvang van geleverde of afgenomen producten en/of diensten (bijvoorbeeld, $\mathrm{x} \%$ van de over het afgelopen boekjaar geleverde waarde aan producten). 